\title{
Socioeconomic Inequalities in Mental Health of Adult Population: Serbian National Health Survey
}

\author{
Milena Santric-Milicevic ${ }^{1}$, Janko Jankovic ${ }^{1}$, Goran Trajkovic ${ }^{2}$, Zorica Terzic-Supic ${ }^{1}$, Uros Babic ${ }^{3}$, Marija Petrovic ${ }^{1}$ \\ ${ }^{1}$ Institute of Social Medicine, Faculty of Medicine University of Belgrade, Belgrade, Serbia \\ ${ }^{2}$ Institute of Medical Statistics and Informatics, Faculty of Medicine University of Belgrade, Belgrade, Serbia \\ ${ }^{3}$ Clinical Center of Serbia, Belgrade, Serbia
}

Background: The global burden of mental disorders is rising. In Serbia, anxiety is the leading cause of disability-adjusted life years. Serbia has no mental health survey at the population level. The information on prevalence of mental disorders and related socioeconomic inequalities are valuable for mental care improvement.

Aims: To explore the prevalence of mental health disorders and socioeconomic inequalities in mental health of adult Serbian population, and to explore whether age years and employment status interact with mental health in urban and rural settlements.

Study Design: Cross-sectional study.

Methods: This study is an additional analysis of Serbian Health Survey 2006 that was carried out with standardized household questionnaires at the representative sample of 7673 randomly selected households -15563 adults. The response rate was $93 \%$. A multivariate logistic regression modeling highlighted the predictors of the 5 item Mental Health Inventory (MHI-5), and of chronic anxiety or depression within eight independent variables (age, gender, type of settlement, marital status and self-perceived health, education, employment status and Wealth Index). The significance level in descriptive statistics, chi square analysis and bivariate and multivariate logistic regressions was set at $\mathrm{p}<0.05$.
Results: Chronic anxiety or depression was seen in $4.9 \%$ of the respondents, and poor MHI-5 in $47 \%$ of respondents. Low education (Odds Ratios 1.32; 95\% confidence intervals $=1.16-1.51)$, unemployment $(1.36$; 1.18-1.56), single status (1.34; 1.23-1.45), and Wealth Index middle class $(1.20 ; 1.08-1.32)$ or poor $(1.33$; 1.21-1.47) were significantly related with poor MHI-5. Unemployed persons in urban settlements had higher odds for poormMHI-5 than unemployed in rural areas $(0.73 ; 0.59-0.89)$. Single $(1.50 ; 1.26-1.78)$, unemployed $(1.39 ; 1.07-1.80)$ and inactive respondents $(1.42 ; 1.10-1.83)$ had a higher odds of chronic anxiety or depression than married individuals, or those with partner, and employed persons. Those with perceived good health status had lower odds for poor MHI-5, chronic anxiety or depression than those whose general health was average and poor.

Conclusion: Almost half of the population assessed their mental health as poor and 5\% had diagnosed chronic anxiety or depression. Multi-sectoral socioeconomic and female-sensitive policies should be wisely tailored to reduce mental health inequalities contributed by differences in age, education, employment, marriage and the wealth status of the adult population.

Keywords: Anxiety, depression, subjective health, socioeconomic factors
Mental disorders reduce a person's ability to work productively, contribute to the community and manage common stresses of life (1). The nature of inequalities in mental health is complex and is affected by the socioeconomic, cultural and environmental conditions, living and working environment, social and community networks, health behaviors, age, gender and heredity factors $(1,2)$. Inequalities in mental health can be both the source and the consequence of inequalities 
in a society (2). Around 450 million people with mental disorders worldwide are at high risk of suffering from inequalities in a society (1). However, socioeconomic inequalities in the mental health of population in the low and middle income countries were insufficiently documented $(2,3)$.

Serbia is the worst performer for anxiety disorders according to the age standardized rates of disability adjuste life years (4). The same period was marked with sociopolitical disturbances such as citizens' conflicts and former Yugoslavia break up, international sanctions, North Atlantic Treaty Organization (NATO) bombing and economic degradation. A number of evidence has pointed to the fact that exposure to immense stresses besides personal traits might influence the occurrence of psychosomatic symptoms and almost complete social dysfunction among Serbian population $(5,6)$. Also, frequent mental disorders among military missions were noticed, despite psychological prevention efforts (7). There are more studies about the mental health of veterans, refugees, and hospitalized patients than about civilians; therefore, national research is important to complete the understanding of the population mental health (8).

The country context also characterizes a mostly rural structure ( $80 \%$ of rural areas is inhabited with $55 \%$ of population) and considerable socioeconomic inequalities in the population (9-11) on the one hand, and increased utilization of mental healthcare at the primary level (Table 1) (12), the highest share of total expenditure for mental healthcare among 40-59 year old health insurees (about $42 \%$, and extensively for psychoactive drugs) (13), and the initiation of deinstutionalization of mental healthcare on the other hand (14). Seeing that adults have bared most of the traumatic events including the consequences of economy failure (job and insurance lost, salary decrease, etc.) and are those who care for older and younger family members, their mental health requires adequate attention and care. However, the relationship between their mental health and demographic and socioeconomic factors has not yet been reported.

This study explored the prevalence of mental health disorders and socioeconomic inequalities in the mental health of the adult Serbian population. Moreover, it explored whether age and employment status interact with mental health in urban and rural settlements.

\section{MATERIALS AND METHODS}

\section{Study design and participants}

Serbia has no mental health survey at the population level yet; thus, additional analysis of the Serbian Health Survey 2006 (15) aimed to describe the population mental health profile (without data on Kosovo and Metohija). The Serbian Health Survey 2006 was performed by the Ministry of Health of the Republic of Serbia $(\mathrm{MoH})$ with the support of the World Bank, the World Health Organization Country Office and the Institute of Public Health of Serbia (IPHS) (15). Since the study design was in accordance with the ethical principles (all participants were informed about the purpose of the study and agreed to participate in the interview) of the MoH Review Board and IPHS, they permitted the survey being conducted during September and October 2006.

A stratified two-stage sampling design was used for 7673 randomly selected households and 15563 adults aged 20 years or more (15). The main sample strata were six geographical regions of Serbia (Vojvodina, Belgrade, West, Central, East and South-East Serbia) which were further divided into urban and rural type settlements with 12 sample strata. The first stage units were 675 enumeration districts defined in the 2002 population Census and selected systematically with probability proportional to their size (probability proportional sam-

TABLE 1. Number of beds, number of specialists and healthcare services for persons with mental and behavioral disorders (ICD-10: F00-F99) in the Republic of Serbia (without data for Kosovo and Metohija)

\begin{tabular}{|c|c|c|c|c|c|c|}
\hline \multirow[b]{2}{*}{ Year } & \multirow{2}{*}{$\begin{array}{c}\text { Hospital beds* } \\
\text { Number }\end{array}$} & \multirow{2}{*}{$\begin{array}{c}\text { Psychiatrists and } \\
\text { neuropsychiatrists }\end{array}$} & \multicolumn{2}{|c|}{$\begin{array}{l}\text { Hospitalization rate } \\
\text { per } 100 \text { population }\end{array}$} & \multicolumn{2}{|c|}{$\begin{array}{l}\text { Number of primary care visits } \\
\text { per } 1000 \text { population aged }\end{array}$} \\
\hline & & & Males & Females & $<19$ years & $\geq 19$ years \\
\hline 2006 & 5527 & 841 & 4.9 & 3.61 & 16.78 & 62.46 \\
\hline 2007 & 5385 & 871 & 4.89 & 3.76 & 19.51 & 76.87 \\
\hline 2008 & 5244 & 855 & 7.85 & 5.69 & 21.00 & 68.52 \\
\hline 2009 & 5290 & 859 & 7.63 & 5.53 & 23.78 & 84.84 \\
\hline 2010 & 5447 & 819 & 8.48 & 6.22 & 26.38 & 91.06 \\
\hline 2011 & 5431 & 831 & 7.85 & 6.06 & 32.40 & 103.63 \\
\hline 2012 & 5268 & 804 & 7.33 & 5.84 & 35.57 & 98.08 \\
\hline
\end{tabular}

*: Hospital beds include beds in general, specialist hospitals, clinics, institutes, clinical-hospital centers and clinical centers but excludes beds in day-hospitals.

**: Number of visits per 1000 population in primary care, for persons aged $<19$ years include visits of chosen doctors in child, youth and schoolchildren health services, while for persons aged $\geq 19$ years only number of visits to "chosen doctors" (gatekeepers) in general practice services and occupational health services. 
TABLE 2. Mental health inventory categories (MHI-5) of the sample ( $\mathrm{N}=14186)$ according to socioeconomic characteristics and self-perceived health

\begin{tabular}{|c|c|c|c|}
\hline \multirow[b]{2}{*}{$\begin{array}{l}\text { Socioeconomic } \\
\text { determinants }\end{array}$} & \multicolumn{3}{|c|}{ Mental health inventory categories (MHI-5) } \\
\hline & $\begin{array}{c}\text { MHI-5 } \\
<68, \mathrm{n}(\%)\end{array}$ & $\begin{array}{c}\text { MHI-5 } \\
\geq 68, \mathrm{n}(\%)\end{array}$ & $\mathrm{p}$ \\
\hline Total & $6867(100)$ & $7319(100)$ & \\
\hline \multicolumn{4}{|l|}{ Gender } \\
\hline Female & $3941(57.4)$ & $3562(48.7)$ & \multirow[b]{2}{*}{$<0.001$} \\
\hline Male & $2926(42.6)$ & $3757(51.3)$ & \\
\hline \multicolumn{4}{|l|}{ Age (years) } \\
\hline $20-29$ & $724(10.5)$ & $1404(19.2)$ & \multirow{6}{*}{$<0.001$} \\
\hline $30-39$ & $887(12.9)$ & $1370(18.7)$ & \\
\hline $40-49$ & $1139(16.6)$ & $1318(18.0)$ & \\
\hline $50-59$ & $1473(21.5)$ & $1347(18.4)$ & \\
\hline $60-69$ & $1173(17.1)$ & $989(13.5)$ & \\
\hline $70+$ & $1471(21.4)$ & $891(12.2)$ & \\
\hline \multicolumn{4}{|l|}{ Marital status } \\
\hline Married/living with & $4540(66.1)$ & $5165(70.6)$ & \multirow{4}{*}{$<0.001$} \\
\hline a partner & & & \\
\hline $\begin{array}{l}\text { Unmarried, divorced, } \\
\text { widowed }\end{array}$ & $2306(33.6)$ & $2128(29.1)$ & \\
\hline Missing & $21(0.3)$ & $26(0.4)$ & \\
\hline \multicolumn{4}{|l|}{ Type of settlement } \\
\hline Urban & $3440(50.1)$ & $3931(53.7)$ & \multirow[b]{2}{*}{$<0.001$} \\
\hline Rural & 3427 (49.9) & $3388(46.3)$ & \\
\hline \multicolumn{4}{|l|}{ Employment status } \\
\hline Employed & $2029(29.5)$ & $3099(42.3)$ & \multirow{4}{*}{$<0.001$} \\
\hline Unemployed & $1226(17.9)$ & $1390(19.0)$ & \\
\hline Inactive & $3606(52.5)$ & $2827(38.6)$ & \\
\hline Missing & $6(0.1)$ & $3(0.1)$ & \\
\hline \multicolumn{4}{|l|}{ Education } \\
\hline High education & $680(9.9)$ & $1117(15.3)$ & \multirow{3}{*}{$<0.001$} \\
\hline Middle education & 2859 (41.6) & $3907(53.4)$ & \\
\hline Low education & $3328(48.5)$ & $2295(31.4)$ & \\
\hline \multicolumn{4}{|l|}{ Wealth Index } \\
\hline Rich & $2049(29.8)$ & 2969 (40.6) & \multirow{3}{*}{$<0.001$} \\
\hline Middle class & $1414(20.6)$ & $1500(20.5)$ & \\
\hline Poor & 3404 (49.6) & $2850(38.9)$ & \\
\hline \multicolumn{4}{|l|}{ Self-perceived health } \\
\hline Good & $2063(30.0)$ & $4277(58.4)$ & \multirow{4}{*}{$<0.001$} \\
\hline Average & $2878(41.9)$ & $2556(34.9)$ & \\
\hline Poor & $1923(28.0)$ & $482(6.6)$ & \\
\hline Missing & $3(0.1)$ & $4(0.1)$ & \\
\hline
\end{tabular}

pling). Second stage units were households, selected by using simple random sampling without replacement method. The number of households selected in each enumeration area was
10, with 3 backup households approached only in case some of the first 10 households were not found. The overall households' and adults' response rates were $87 \%$ (6156 households) and 93\% (14522 respondents with 6858 males and 7664 females), respectively (15).

\section{Instruments}

Demographic, socioeconomic, self-perceived general health and mental health data of respondents were obtained by personal interview, and household information by questionnaire, which was designed based on the World Health Organization (WHO) Health Survey of 2002 and SF-36 (15-17). More details about the interview and questionnaire are described elsewhere $(9,15)$.

\section{Variables}

Two measures of mental health were used as the dependent variables: the 5 item Mental Health Inventory (MHI-5) $(18,19)$ and self-reported presence or absence of clinically diagnosed chronic anxiety or depression.

The MHI-5 described psychological distress of respondents on a 6-point scale (1-point="all time" and 6-point="none of the time") according to their answers on questions whether they were nervous, happy, calm and peaceful, down in dumps, downhearted or blue in the last four weeks (15). In total, 14186 respondents provided complete answers to those questions. The sum of question scores was transformed to a 0-100 scale, where the final MHI-5 score of 0 indicates the worst mental health, and a score of 100 represents optimal mental health. For the purpose of the analyses, this was transformed into binary variable with the median (20) as a cut-off score (i.e. 68; $<68$ was poor mental health and $\geq 68$ was good mental health).

The second mental health measure was a dichotomous variable indicating self-reported presence or absence of chronic anxiety or depression that was clinically diagnosed in the last 12 months prior to the interview. Complete answers on that question were given by 14494 respondents.

Independent variables were the following: age intervals (2029 years, 3039 years etc.); gender; type of settlement; marital status; self-perceived health (good, average or poor); level of education (according to the International Standard Classification of Education, high level refers to college and university degree; medium level to secondary school, and low level to no school or incomplete primary school and primary school); employment (employed, unemployed and inactive respondents-pensioners, unable to work or inactive due to other reasons); and the Demographic and Health Survey Wealth Index, hereinafter Wealth Index (rich, middle class and poor) $(9-11,15)$. The urban/rural classification of settlements is based on decisions at the municipal level, whereby municipalities that have an urban master plan are declared as "urban" settlement. All settlements not declared 
TABLE 3. Depression or anxiety categories of the sample $(\mathrm{N}=14494)$ according to socioeconomic characteristics and self-perceived health

\begin{tabular}{|c|c|c|c|}
\hline $\begin{array}{l}\text { Socioeconomic } \\
\text { determinants }\end{array}$ & $\begin{array}{l}\text { Chronic anxiety or } \\
\text { depression, } \mathrm{n}(\%)\end{array}$ & $\begin{array}{c}\text { No chronic } \\
\text { anxiety or } \\
\text { depression, } \mathrm{n}(\%)\end{array}$ & $\mathrm{p}$ \\
\hline Total & $713(100)$ & $13781(100)$ & \\
\hline \multicolumn{4}{|l|}{ Gender } \\
\hline Female & $487(68.3)$ & $7163(52.0)$ & \multirow[b]{2}{*}{$<0.001$} \\
\hline Male & $226(31.7)$ & $6618(48.0)$ & \\
\hline \multicolumn{4}{|l|}{ Age (years) } \\
\hline $20-29$ & $34(4.8)$ & 2145 (15.6) & \multirow{6}{*}{$<0.001$} \\
\hline $30-39$ & $68(9.5)$ & $2234(16.2)$ & \\
\hline $40-49$ & $120(16.8)$ & $2389(17.3)$ & \\
\hline $50-59$ & $181(25.4)$ & $2688(19.5)$ & \\
\hline $60-69$ & $137(19.2)$ & $2068(15.0)$ & \\
\hline $70+$ & $173(24.3)$ & 2257 (16.4) & \\
\hline \multicolumn{4}{|l|}{ Marital status } \\
\hline $\begin{array}{l}\text { Married/living with } \\
\text { a partner }\end{array}$ & $435(61.0)$ & $9463(68.7)$ & \multirow{3}{*}{$<0.001$} \\
\hline $\begin{array}{l}\text { Unmarried, divorced, } \\
\text { widowed }\end{array}$ & $276(38.7)$ & $4269(31.0)$ & \\
\hline Missing & $2(0.3)$ & $49(0.4)$ & \\
\hline \multicolumn{4}{|l|}{ Type of settlement } \\
\hline Urban & $340(47.7)$ & $7178(52.1)$ & \multirow[b]{2}{*}{$<0.001$} \\
\hline Rural & $373(52.3)$ & $6603(47.9)$ & \\
\hline \multicolumn{4}{|l|}{ Employment status } \\
\hline Employed & $145(20.3)$ & $5098(37.0)$ & \multirow{4}{*}{$<0.00$} \\
\hline Unemployed & $119(16.7)$ & $2545(18.5)$ & \\
\hline Inactive & $449(63.0)$ & $6127(44.5)$ & \\
\hline Missing & / & $11(0.1)$ & \\
\hline \multicolumn{4}{|l|}{ Education } \\
\hline High education & $58(8.1)$ & $1776(12.9)$ & \multirow{3}{*}{$<0.001$} \\
\hline Middle education & $244(34.2)$ & $6684(48.5)$ & \\
\hline Low education & $411(57.6)$ & $5321(38.6)$ & \\
\hline \multicolumn{4}{|l|}{ Wealth Index } \\
\hline Rich & $189(26.5)$ & $4968(36.0)$ & \multirow{3}{*}{$<0.001$} \\
\hline Middle class & $154(21.6)$ & $2852(20.7)$ & \\
\hline Poor & $370(51.9)$ & $5961(43.3)$ & \\
\hline \multicolumn{4}{|l|}{ Self-perceived health } \\
\hline Good & $92(12.9)$ & $6393(46.4)$ & \multirow{4}{*}{$<0.001$} \\
\hline Average & $277(38.8)$ & $5234(38.0)$ & \\
\hline Poor & $341(47.8)$ & $2130(15.5)$ & \\
\hline Missing & $3(0.4)$ & $24(0.1)$ & \\
\hline
\end{tabular}

Chi-square test was used.

as "urban" were automatically considered rural. The Wealth Index calculation procedure was described in detail elsewhere $(9-11,21)$.
TABLE 4. Multiple logistic regression models for persons with poor mental health (MHI-5 <68) as the dependent variable

\begin{tabular}{lccc}
\hline Socioeconomic determinants & $\mathrm{b}$ & $\mathrm{p}$ & OR $(95 \% \mathrm{CI})$ \\
\hline Gender & & & \\
Female & & & 1 (reference) \\
Male & -0.17 & $<0.001$ & $0.84(0.78-0.91)$ \\
Age (years) & & & \\
20-29 & & & 1 (reference) \\
$30-39$ & 0.25 & $<0.001$ & $1.28(1.12-1.46)$ \\
$40-49$ & 0.37 & $<0.001$ & $1.45(1.26-1.66)$ \\
$50-59$ & 0.36 & $<0.001$ & $1.43(1.25-1.63)$ \\
$60-69$ & 0.18 & 0.024 & $1.20(1.02-1.40)$ \\
$70+$ & 0.22 & 0.007 & $1.24(1.06-1.46)$
\end{tabular}

Marital status

Married/living with a partner

1 (reference)

Unmarried, divorced, widowed

$0.29<0.001 \quad 1.34(1.23-1.45)$

Type of settlement

Urban

Rural

1 (reference)

Employment status

Employed

Unemployed

Inactive

$-0.01 \quad 0.908 \quad 0.99(0.88-1.13)$

Interaction term Employment

status $\times$ type of settlement

Unemployed $\times$ rural

$\begin{array}{lll}-0.32 & 0.002 & 0.73(0.59-0.89)\end{array}$

Inactive $\times$ rural

$\begin{array}{lll}-0.08 & 0.350 & 0.93(0.79-1.09)\end{array}$

Education

High education

1 (reference)

Middle education

$0.08 \quad 0.156 \quad 1.09(0.97-1.22)$

Low education

$0.28<0.001 \quad 1.32(1.16-1.51)$

Wealth index

Rich

1 (reference)

Middle class

$0.18 \quad 0.001 \quad 1.19(1.08-1.32)$

Poor

$0.29<0.001 \quad 1.33(1.21-1.47)$

Self-perceived health

Good

1 (reference)

Average $\quad 0.76 \quad<0.001 \quad 2.13(1.96-2.31)$

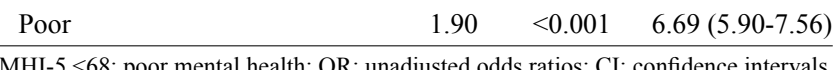

\section{Statistical analyses}

Analysis of the study data was performed using descriptive statistics, Chi-square test for testing differences in proportions, and multiple logistic regressions for modeling relationships between mental health status, as a dependent variable, and participant characteristics as independent variables. The 
TABLE 5. Multiple logistic regression models of socioeconomic determinants for persons with chronic anxiety or depression as the dependent variable

\begin{tabular}{|c|c|c|c|}
\hline Socioeconomic determinants & $\mathrm{b}$ & $\mathrm{p}$ & OR $(95 \% \mathrm{CI})$ \\
\hline \multicolumn{4}{|l|}{ Gender } \\
\hline Female & & & 1 (reference) \\
\hline Male & -0.38 & $<0.001$ & $0.68(0.57-0.81)$ \\
\hline \multicolumn{4}{|l|}{ Age (years) } \\
\hline $20-29$ & & & 1 (reference) \\
\hline $30-39$ & 0.61 & 0.006 & $1.84(1.19-2.83)$ \\
\hline $40-49$ & 0.86 & $<0.001$ & $2.35(1.56-3.54)$ \\
\hline $50-59$ & 0.77 & $<0.001$ & $2.15(1.44-3.22)$ \\
\hline $60-69$ & 0.36 & 0.106 & $1.43(0.93-2.20)$ \\
\hline $70+$ & 0.18 & 0.410 & $1.20(0.78-1.84)$ \\
\hline \multicolumn{4}{|l|}{ Marital status } \\
\hline Married/living with a partner & & & 1 (reference) \\
\hline Unmarried, divorced, widowed & 0.41 & $<0.001$ & $1.50(1.26-1.78)$ \\
\hline \multicolumn{4}{|l|}{ Type of settlement } \\
\hline Urban & & & 1 (reference) \\
\hline Rural & 0.04 & 0.632 & $1.05(0.87-1.25)$ \\
\hline \multicolumn{4}{|l|}{ Employment status } \\
\hline Employed & & & 1 (reference) \\
\hline Unemployed & 0.33 & 0.014 & $1.39(1.07-1.80)$ \\
\hline Inactive & 0.35 & 0.007 & $1.42(1.10-1.83)$ \\
\hline \multicolumn{4}{|l|}{ Education } \\
\hline High education & & & 1 (reference) \\
\hline Middle education & -0.06 & 0.706 & $0.94(0.70-1.28)$ \\
\hline Low education & 0.05 & 0.757 & $1.05(0.76-1.46)$ \\
\hline \multicolumn{4}{|l|}{ Wealth Index } \\
\hline Rich & & & 1 (reference) \\
\hline Middle class & 0.11 & 0.350 & $1.12(0.88-1.42)$ \\
\hline Poor & 0.07 & 0.560 & $1.07(0.85-1.34)$ \\
\hline \multicolumn{4}{|l|}{ Self-perceived health } \\
\hline Good & & & 1 (reference) \\
\hline Average & 1.15 & $<0.001$ & $3.15(2.45-4.06)$ \\
\hline Poor & 2.20 & $<0.001$ & $9.06(6.94-11.83)$ \\
\hline
\end{tabular}

level of significance (alpha level) in all analyses was set at 0.05 . Statistical analysis process of the study was done with IBM SPSS Statistics for Windows, Version 20.0 (IBM Corporation; New York, USA) (22).

\section{RESULTS}

Almost half of the sample (47\%) had poor mental health, MHI-5 $<68$ (Table 2). Among them, there were more females, more persons older than 50 years and more persons married or living with a partner. More were from urban settlements, unemployed and inactive, and belonged to the most deprived group. Fewer had a high education level and perceived their health as good. Respondents' MHI-5 categories significantly differed regarding all investigated socioeconomic variables and self-perceived health $(\mathrm{p}<0.001)$.

Chronic anxiety or depression was reported in $4.9 \%$ of the respondents (Table 3 ) and among them there were more females, aged 50 years or over and more married persons or with a partner. Most of the respondents were inactive, had low education levels, settled in rural areas, were poor and had a perception of poor general health. Detected socioeconomic differences between those persons with diagnosed chronic anxiety or depression and those without a diagnosis were significant $(\mathrm{p}<0.001)$.

Males in Serbia were $16 \%$ less likely to have MHI- $5<68$ than females (OR $=0.84 ; 95 \%$ CI: $0.78-0.91)$ (Table 4). Single persons were more likely to have MHI-5 $<68$ by $34 \%$ $(1.34 ; 1.23-1.45)$ than persons who were married or with a partner. With each increase in age intervals, the likelihood to have MHI-5 $<68$ increased as well. In comparison to those aged 2029 years, the highest OR increases were recorded for persons aged $40-49$ years by $45 \%(1.45 ; 1.26-1.66)$, and respondents aged $50-59$ years by $43 \%(1.43 ; 1.25-1.63)$. In comparison to employed respondents, unemployed individuals were more likely to have MHI-5 $<68(1.36 ; 1.18-1.56)$. Respondents with a low level of education in comparison to high educated respondents had an increased odds of having MHI $-5<68$ by $32 \%(1.32 ; 1.161 .51)$.

Poor and middle class respondents also had an increased likelihood of having MHI-5 $<68$ than rich persons $(1.33 ; 1.21$ 1.47; and 1.19; 1.08-1.32). Those that perceived their health as average and poor were about twofold $(2.13 ; 1.96-2.31)$ and sixfold $(6.69 ; 5.90-7.58)$ more likely to have MHI-5 $<68$ than respondents who self-perceived good health status. Unemployed persons in urban settlements had lower odds of MHI-5 $<68$ than the unemployed in rural areas $(0.73 ; 0.59-0.89)$.

Males were $32 \%$ less likely to have chronic anxiety or depression than females $(0.68 ; 0.57-0.81)$ (Table 5). Single respondents were $50 \%$ more likely to have chronic anxiety or depression than persons who were married or with a partner (1.50; 1.26-1.78). In comparison to respondents aged 20-29 years, the likelihood of having chronic anxiety or depression was the highest among those aged $40-49$ years, by $135 \%(2.35 ; 1.56-$ $3.54)$, than $115 \%$ higher for aged $50-59$ years $(2.15 ; 1.44-3.22)$ and $84 \%$ for persons $30-39$ years $(1.84 ; 1.19-2.83)$. Higher odds for chronic anxiety or depression had inactive respondents or those with no employment than the employed $(1.42 ; 1.10$ 1.83 and $1.39 ; 1.07-1.80)$. Those that perceived their health to 
be average or poor were about threefold $(3.15 ; 2.45-4.06)$ and nine-fold $(9.06 ; 6.94-11.83)$ more likely to have chronic anxiety or depression than respondents with self-perception of good health. The interactions between the age years and the type of settlement as well as between the employment status and the type of settlement were not significant predictors for chronic anxiety or depression in respondents $(\mathrm{p}>005)$.

\section{DISCUSSION}

Almost half of the population assessed their mental health as poor, and 5\% had diagnosed chronic anxiety or depression. The investigated mental disorders were unequally distributed among Serbian population; they were significantly more frequent among females, people older than 50 years, low educated, inactive and most deprived persons. Although it is difficult to make a straightforward comparison with epidemiological surveys due to the differences in methods and instruments applied, study results correspond well to the international literature (1,2,23-26).

Possible predictors for poor mental health were consistent with the predictors of diagnosis of chronic anxiety or depressions, implying that both subjectively and objectively measured poor mental health co-occur in the same socioeconomically disadvantaged population groups. Furthermore, this is a common feature of developing countries (27). According to the size of the odds ratio, highest ratios for having poor mental health or chronic anxiety and depression were seen in individuals who did not perceive their health to be good, who were aged 40 years and older (in particular those 50-59 years old), who were single, unemployed, inactive females. Most individuals with poor mental and general health are likely to seek health services, which may explain the increased utilization of mental care at the primary level and the related growth of health expenditures in Serbia.

Gender-related odds ratios for mental health disorders were relatively consistent across countries despite substantial variation in traditional female gender role (23). Being a female was also a significant predictor of chronic medical illness and psychiatric multi morbidity in Australia (24), Finland (25), Sweden (26), Bangladesh (28), and Southeast Brazil (29), perhaps because of higher workload, low position in some cultures and higher level of stress hormones $(25,30)$. Although female roles changed with the time, the odds ratios remained relatively stable for more than half a century (23). Noteworthy evidence implies that the mental health of females and males is equally endangered by unsatisfactory basic life conditions (28).

Findings about the mental health of urban and rural populations are contradictory. Our study provided evidence that the type of settlement is not a significant predictor of mental health status in spite of the fact that rural areas were statistically more inhabited with persons with poor mental health, chronic anxiety or depression. However, being employed was more important for good mental health among urban than rural residents. Some authors have reported more frequent depression and suicides in rural settings (31), while others have described that residents of rural or remote settlements have better mental health (32). The interactions between the age years and the type of settlement were not significant predictors for the mental health of Serbian adults, in spite of demographic ageing and the depopulation of rural settlements.

The odds of having poor mental health increased with age interval, probably because of the number of years between the onset of most mental disorders and the effective treatment $(23,33)$. In our study, odds ratios for poor mental health and depression and anxiety disorders were high for adults in age intervals 40-49 years and 50-59 years, suggesting that those individuals were extremely exposed to social and economic shocks throughout the 1990s and 2000s. Interestingly, in Sweden, good mental health was found among people aged 65-74 years (26). In line with other researchers $(24,25)$, we found a high likelihood for poor mental health among single persons, low educated and unemployed, but others provided evidence that never married persons (29) and unemployed individuals (26) have a negative association with mental morbidity, perhaps due to the age effect. Given the positive association between poor health and mental disorders (34), respondents who perceived their general health as poor had the highest odds ratios for MHI-5<68 and chronic anxiety or depression, implying that adult residents of Serbia need considerably better healthcare, including mental health promotion.

Similar to our findings, Priebe and associates (5) found the high overall prevalence of mental disorders in Kosovo $(62.2 \%)$, Bosnia and Herzegovina (48\%), Croatia (39.8\%) and the Republic of Macedonia (21.5\%). They explained that higher rates of anxiety disorders and posttraumatic stress disorder were associated with older age, female sex, unemployment and traumatic experiences during and after the last army conflicts. In Greece, the prevalence of general psychiatric morbidity was $14 \%$, of which the most common were generalized anxiety disorder and depression (4.1\% and 2.9\%, respectively) (35). Turkey, in contrast to Serbia, had the Mental Health Profile Research but it has not been repeated to allow impact analysis of ongoing social and demographic transition, natural disasters, social inequality, rapid urbanization, migration, cultural and other factors on households and individuals with these chronic health problems (36). Within the affluent research on psychiatric epidemiology in Turkey, the novel research on mental health is limited, although psychiatric disorders are among the five of the top ten 
diseases that cause severe disability in Turkey (36). In general, the research on mental health at national level in the countries of Southeastern Europe is rare.

The study has a few methodological limitations. No conclusion can be drawn regarding the causal relationship due to a cross-sectional design of the study and temporal relations found between independent and depended variables. A range of methods can be used for division of the MHI-5 scale into two categories (20), but a decision about the optimal cutoff point for predicting mental disorders is unclear (37). For example, for major depression, it may be 52 or 56 , but for other diagnostic groups there is no widely accepted recommendation for the cut-off point (37), i.e. psychological distress analyzed in this study. The application of median as a cut of point of MHI-5 scale to obtain dichotomous outcome variable may increase the probability of a Type II error and shortfall of statistical power (38). In addition, instead of reviewing the medical records and providing objective data, the interviewers asked respondents to voluntary reveal their private information about clinical diagnoses of depression during the survey. Therefore, findings might be under- or over-estimated because they were based on respondents' answers and perceptions, which reflected the respondent's memory, awareness or readiness to disclose personal issues. These concerns were somewhat reduced by the fact that our results were collected with a standardized questionnaire and were based on the representative population sample with very small number of missing data. The study findings should not be generalized to the youth population, to a number of other types of mental disorders or variables (risk health behaviors, social support and personality traits) that were not assessed in this study.

\section{Implications for policy and practice}

From the global point of view, although mental disorders may not be more frequent now than in previous periods, they account for approximately $12 \%$ of the global burden of disease (39) and contribute to increased healthcare costs even many years later (40).

This study is the first large-scale study that has emphasized a great burden of poor mental health in Serbian adult population and has documented the existence of socioeconomic inequalities in mental health of Serbia. In the absence of a complete mental health register and population-based mental health studies, the National Health Survey 2006 was the unique opportunity and the best source to obtain valid information about population mental health. This study allows the comparative assessment of mental health inequalities with future surveys, and may be used as a standing point for impact evaluations of social and economic interventions aimed at reducing the inequalities in the mental health of the population. The new results of the national health focused mainly on residents' perception of depression severity (41), despite the fact that Serbia was not managing well enough with chronic anxiety disorders as it was doing with the major depressive disorders (4). In particular, the study results are important and up to date, as this was single population based study so far that provide valid estimates to policy makers about poor mental health, chronic anxiety and depression at the national level and population socioeconomic capability to bear the envisioned mental care changes. In light of the large-scale transformation of mental health care that is ongoing in Serbia, as in Turkey and other Balkan countries, population based studies are vital. Based on the strength of observed associations, findings can be used to inform decision makers about the considerable need for economic support and better health care among persons with poor mental health. Due to the chronic nature of mental problems, people have to be protected for a long term from out-of-pocket payments for a specific treatment or service. Multisectoral interventions and international, regional initiatives and policies should aim at the whole population with mental health promotion, while households, families and carers of a mentally ill person(s) needs wise capacity building to reduce the impacts of adversity. Investment in education should target female adults. Furthermore, for the equality in mental health improvement, the study results suggest assessing socioeconomic status while selecting patients whose mental care is to be provided at a community level within the deinstutionalization of mental care. The involvement of users and carers in the process of planning, implementation and running of community mental health care was seen as the path to social inclusion (42). Future research should explore the profile of risk behavior and social support of persons with mental health problems and the effects of mental health care utilization in settlements where seeking mental care might be stigmatized.

Ethics Committee Approval: Ethics committee approval was received for this study from the ethics committee of the Review Board of the Ministry of Health of the Republic of Serbia and the Institute of Public Health of Serbia 'Dr Milan Jovanovic Batut', which permitted the National Health Survey design and conduct.

\section{Informed Consent: N/A.}

Peer-review: Externally peer-reviewed.

Author contributions: Concept - M.S.M., J.J., G.T.; Design M.S.M., J.J., G.T.; Supervision - M.S.M., Z.T.S., G.T.; Resource M.S.M., Z.T.S., J.J.; Materials - J.J., Z.T.S., M.T.; Data Collection \&/or Processing - J.J., G.T., U.B.; Analysis \&/or Interpretation M.S.M., U.B., M.P.; Literature Search - J.J., M.P., U.B., G.T., Z.T.S.; Writing - M.S.M., J.J., G.T., U.B., M.P., Z.T.S.; Critical Reviews M.S.M., G.T., Z.T.S. 
Conflict of Interest: No conflict of interest was declared by the authors.

Financial Disclosure: The study is secondary data analysis of the 2006 National Health Survey for the population of Serbia (without data on Kosovo and Metohija) that was carried out by the Ministry of Health of the Republic of Serbia with financial and professional support of the World Bank, the World Health Organization Regional Office for Europe (country office Serbia), the Institute of Public Health of Serbia 'Dr Milan Jovanovic Batut'. Authors were supported by the Ministry of Education, Science and Technology of the Republic of Serbia (Grant No. 175087 and Grant No. 175025).

\section{REFERENCES}

1. Friedli L. Mental health, resilience and inequalities. Copenhagen, Denmark: World Health Organization Regional Office for Europe; 2009.

2. Patel V, Lund C, Hatherill S, Plagerson S, Corrigall J, Fundl M, et al. Mental disorders: equity and social determinants. In: Blas A, Kurup AS, editors. Equity, Social Determinants and Public Health Programs. Geneva: WHO Press; 2010:115-34.

3. Morasae EK, Forouzan AS, Majdzadeh R, Asadi-Lari M, Noorbala AA, Hosseinpoor AR. Understanding determinants of socioeconomic inequality in mental health in Iran's capital, Teheran: a concentration index decomposition approach. Int J Equity Health 2012;11-8.

4. IHME GBD Country Report Serbia. http://www.healthdata.org/ sites/default/files/files/country_profiles/GBD/ihme_gbd_country_report_serbia.pdf

5. Priebe S, Bogic M, Ajdukovic D, Franciskovic T, Galeazzi GM, Kucukalic A, et al. Mental disorders following war in the Balkans a study in 5 countries. Arch Gen Psychiatry 2010;67:51828. [CrossRef]

6. Mirković M, Simić S, Trajković G. Assessment of mental health in adults of the northern part of the city of Kosovska Mitrovica. Vojnosanit Pregl 2012;69:747-52. [CrossRef]

7. Kowalski JT, Hauffa R, Jacobs H, Höllmer H, Gerber WD, Zimmermann P. Deployment-related stress disorder in german soldiers: utilization of psychiatric and psychotherapeutic treatment. Dtsch Arztebl Int 2012;109:569-75.

8. Gerritsen AA, Bramsen I, Devillé W, van Willigen LH, Hovens JE, van der Ploeg HM. Physical and mental health of Afghan, Iranian and Somali asylum seekers and refugees living in the Netherlands. Soc Psychiatry Psychiatr Epidemiol 2006;41:1826. [CrossRef]

9. Jankovic J, Simic S, Marinkovic J. Inequalities that hurt: demographic, socio-economic and health status inequalities in the utilization of health services in Serbia. Eur J Public Health 2010;20:389-96. [CrossRef]

10. Jankovic J, Marinkovic J, Simic S. Utility of data from a national health survey: do socioeconomic inequalities in morbidity exist in Serbia? Scand J Public Health 2011;39:230-8. [CrossRef]
11. Janković J, Janević T, von dem Knesebeck O. Socioeconomic inequalities, health damaging behavior, and self-perceived health in Serbia: a cross-sectional study. Croat Med J 2012;53:254-62. [CrossRef]

12. Institute of Public Health of Serbia. Health Statistical Yearbooks of the Republic of Serbia 2006-2012. Belgrade: Institute of Public Health of Serbia, 2007-2013. http://www.batut.org.rs/index. php? content $=279$

13. The Serbian Health Insurance Fund. Electronic databases of the Department for development and information technologies: Total health expenditures for F00-F99, by age, sex and type of services of insurers in the period 2010-2013. www.rfzo.rs

14. Serbian Government of the Republic of Serbia. Strategy on Development of Mental Health Protection. Official Gazzete 2007:8. http://www.gs.gov.rs/english/strategije-vs.html

15. Ministry of Health of the Republic of Serbia. Belgrade: Ministry of Health of the Republic of Serbia; 2007. http://www. batut. org.rs/download/publikacije/National $\% 20$ Health\%20Survey\% 20Serbia\%202006.pdf

16. World Health Organization. Health statistics and information systems. World Health Survey. http://www.who.int/healthinfo/ survey/en

17. SF-36.org. A community for measuring health outcomes using SF tools. SF Surveys: http://www.sf-36.org

18. Thorsen SV, Rugulies R, Hjarsbech PU, Bjorner JB. The predictive value of mental health for long-term sickness absence: the Major Depression Inventory (MDI) and the Mental Health Inventory (MHI-5) compared. BMC Med Res Methodol 2013;13:115. [CrossRef]

19. Mental Health National Outcomes and Casemix Collection. Overview of clinician-rated and consumer self-report measures, Version 1.50. Canberra: Department of Health and Ageing; 2003.

20. Foster JJ, Barkus E, Yavorsky C. Understanding and Using Advanced Statistics: A Practical Guide for Students. London: SAGE Publications Ltd; 2006: p. 57. [CrossRef]

21. Rutstein SO, Johnson K. DHS Comparative Reports No. 6. The DHS Wealth Index. Calverton, Maryland: ORC Macro; 2004. http://www.measuredhs.com/pubs/pdf/CR6/CR6.pdf

22. IBM Corp. Released 2011. IBM SPSS Statistics for Windows, Version 20.0. Armonk, NY: IBM Corp. http://www-01.ibm.com/ support/docview.wss?uid=swg21476197

23. Seedat S, Scott KM, Angermeyer MC, Berglund P, Bromet EJ, Brugha TS, et al. Cross-national associations between gender and mental disorders in the World Health Organization World Mental Health Surveys. Arch Gen Psychiatry 2009;66:785-95. [CrossRef]

24. McEvoy PM, Grove R, Slade T. Epidemiology of anxiety disorders in the Australian general population: findings of the 2007 Australian National Survey of Mental Health and Wellbeing. Aust N Z J Psychiatry 2011;45:957-67. [CrossRef]

25. Joutsenniemi K, Martelin T, Martikainen P, Pirkola S, Koskinen $\mathrm{S}$. Living arrangements and mental health in Finland. $J$ Epidemiol Community Health 2005;60:468-75. [CrossRef] 
26. Molarius A, Berglund B, Eriksson C, Eriksson HG, LindénBoström M, Nordström E, et al. Mental health symptoms in relation to socio-economic conditions and lifestyle factors - a population-based study in Sweden. BMC Public Health 2009;9:302. [CrossRef]

27. Lopez AD, Mathers C, Ezzati M, Jamison D, Murray C. Global burden of disease and risk factors. Washington (DC): World Bank; 2006. [CrossRef]

28. Gruebner O, Khan MMH, Lautenbach S, Müller D, Krämer A, Lakes T, et al. Mental health in the slums of Dhaka - a geoepidemiological study. BMC Public Health 2012;12:177. [CrossRef]

29. Andrade LH, Bense-or IM, Viana MC, Andreoni S, Wang YP. Clustering of psychiatric and somatic illnesses in the general population: multimorbidity and socioeconomic correlates. Braz J Med Biol Res 2010;43:483-91. [CrossRef]

30. Lundberg U, Frankenhauser M. Stress and workload of men and women in high-ranking positions. J Occup Health Psychol 1999;4:142-51. [CrossRef]

31. Zhang J, Xiao S, Zhou L. Mental Disorders and Suicide Among Young Rural Chinese: A Case-Control Psychological Autopsy Study. Am J Psychiatry 2010;167:773-81. [CrossRef]

32. Riva M, Bambra C, Curtis S, Gauvin L. Collective resources or local social inequalities? Examining the social determinants of mental health in rural areas. Eur J Public Health 2011;21:197203. [CrossRef]

33. de Girolamo G, Dagani J, Purcell R, Cocchi A, McGorry PD. Age of onset of mental disorders and use of mental health services: needs, opportunities and obstacles. Epidemiol Psychiatr Sci 2012;21:47-57. [CrossRef]

34. Wu S, Wang R, Zhao Y, Ma X, Wu M, Yan M, et al. The relationship between self-rated health and objective health status: a population-based study. BMC Public Health 2013;13:320.
[CrossRef]

35. Skapinakis P, Bellos S, Koupidis S, Grammatikopoulos I, Theodorakis PN, Mavreas V. Prevalence and sociodemographic associations of common mental disorders in a nationally representative sample of the general population of Greece. BMC Psychiatry 2013;4;13:163.

36. Binbay T, Direk N, Aker T, Akvardar Y, Alptekin K, Cimilli $\mathrm{C}$, et al. Psychiatric Epidemiology in Turkey: Main Advances in Recent Studies and Future Directions. Turk Psikiyatri Derg 2014;25:264-81.

37. Strand BH, Dalgard OS, Tambs K, Rognerud M. Measuring the mental health status of the Norwegian population: A comparison of the instruments SCL-25, SCL-10, SCL-5 and MHI-5 (SF-36) Nord J Psychiatry 2003;57:113-8. [CrossRef]

38. Streiner DL. Breaking up is hard to do: The heartbreak of dichotomizing continuous data. Can J Psychiatry 2002;47:262-6.

39. Collins PY, Patel V, Joestl SS, March D, Insel TR, Daar AS, et al. Grand challenges in global mental health. Nature 2011;475:2730. [CrossRef]

40. Sabes-Figuera R, McCrone P, Bogic M, Ajdukovic D, Franciskovic $\mathrm{T}$, Colombini N, et al. Long-term impact of war on healthcare costs: an eight-country study. PLoS One 2012;7:e29603. [CrossRef]

41. The Institute of Public Health of Serbia "Dr Milan Jovanovic Batut". Results of the National Health Survey of the Republic of Serbia 2013. http://www.batut.org.rs/download/publikacije/201 3SerbiaHealthSurvey.pdf

42. World Health Organization / Regional Office for Europe Transforming mental health care in Turkey. http:/ww.euro.who.int/ en/countries/turkey/news/news/2013/10/ transforming-mentalhealth-care-in-turkey 